\title{
THE INVERTIBILITY FOR LINEAR COMBINATIONS OF BOUNDED LINEAR OPERATORS WITH CLOSED RANGE
}

\author{
Guojun Hai, Chegen Bao and Alatancang Chen
}

Abstract. In this paper, it is given that the sufficient and necessary conditions for the invertibility of linear combinations of bounded linear operators with closed range. Furthermore, some related results are obtained.

Mathematics subject classification (2010): 47A05, 47A10, 47B99.

Keywords and phrases: Invertibility, bounded operator, linear combination, EP operator.

\section{REFERENCES}

[1] M. L. Ariasa, G. Coracha, M. C. GonZalez, Additivity properties of operator ranges, Linear Algebra Appl. 439 (2013), 3581-3590.

[2] J. K. BAKSALARY, O. M. BAKSALARY, Nonsingularity of linear combinations of idempotent matrices, Linear Algebra Appl. 388 (2004), 25-29.

[3] D. BuckholtZ, Inverting the difference of Hilbert space projections, Amer. Math. Monthly 104 (1997), 60-61.

[4] S. L. Campbell, C. D. MeYer, EP operators and generalized inverses, Canad. Math. Bull. 18 (1975), 327-333.

[5] J. B. ConwaY, A course in Functional Analysis, Springer-Verlag, New York, 1990.

[6] D. S. CvetKoviĆ-ILIĆ, C. Deng, The Drazin invertibility of the difference and the sum of two idempotent operators, J. Comput. Appl. Math. 233 (2010), 1717-1722.

[7] C. DENG, The Drazin inverses of sum and difference of idempotents, Linear Algebra Appl. 430 (2009), $1282-1291$.

[8] C. Deng, Y. WeI, Further results on the Moore-Penrose invertibility of projectors and its applications, Linear Multilinear Algebra 60 (2012), 109-129.

[9] D. S. DJORDJEviĆ, Products of EP operators on Hilbert spaces, Proc. Amer. Math. Soc. 129 (2001), 1727-1731.

[10] D. S. DJORDJEvić, Characterizations of normal, hyponormal and EP operators, J. Math. Anal. Appl. 329 (2007), 1181-1190.

[11] H. Du, X. YAO, C. DENG, Invertibility of linear combinations of two idempotents, Proc. Amer. Math. Soc. 134 (2005), 1451-1457.

[12] H. Du, C. DENG, Moore-Penrose inverses of products and differences of orthogonal projections, Acta Anal. Funct. Appl. 8 (2006), 104-109.

[13] H. Du, C. Deng, M. MbeKhtA, V. MÜller, On spectral properties of linear combinations of idempotents, Studia Math. 180 (2007), 211-217.

[14] D. Drivaliaris, S. Karanasios, D. Pappas, Factorizations of EP operators, Linear Algebra Appl. 429 (2008), 1555-1567.

[15] P. A. Fillmore, J. P. Williams, On operator ranges, Adv. Math. 7 (1971), 254-281.

[16] H. GAU, P. WU, Fredholmness of linear combinations of two idempotents, Integral Equations Operator Theory 59 (2007), 579-583.

[17] J. Gross, G. TRENKLER, Nonsingularity of the difference of two oblique projectors, SIAM J. Matrix Anal. Appl. 21 (1999), 390-395.

[18] R. E. HaRtwig, I. J. KatZ, On products of EP matrices, Linear Algebra Appl. 252 (1997), 339-345. 
[19] J. J. Koliha, V. RAKOČEviĆ, I. STRŠKRABA, The difference and sum of projectors, Linear Algebra Appl. 388 (2004), 279-288.

[20] J. J. Koliha, V. RAKočEvić, The nullity and rank of linear combinations of idempotent matrices, Linear Algebra Appl. 418 (2006), 11-14.

[21] J. J. Koliha, V. RAKočEvić, Stability Theorems for Linear Combinations of Idempotents, Integral Equations Operator Theory $\mathbf{5 8}$ (2007), 597-601.

[22] M. TošIć, D. S. CVeTKOvić-ILIĆ, Invertibility of a linear combination of two matrices and partial orderings, Appl. Math. Comput. 218 (2013), 4651-4657. 